\title{
Pre-transplant HLA Antibodies and Delayed Graft Function in the Current Era of Kidney Transplantation
}

\section{OPEN ACCESS}

Edited by:

Ilias Doxiadis,

University Hospital Leipzig, Germany

Reviewed by:

Benedetto Bruno,

University of Turin, Italy

Josefina M. Alberu,

Escuela de Medicina y Ciencias de la

Salud Tec Salud, Tecnológico de

Monterrey, Mexico

*Correspondence:

Caner Süsal

caner.suesal@med.uni-heidelberg.de

Specialty section:

This article was submitted to Alloimmunity and Transplantation,

a section of the journal

Frontiers in Immunology

Received: 29 March 2020

Accepted: 13 July 2020

Published: 26 August 2020

Citation:

Morath C, Döhler B, Kälble F, Pego da

Silva L, Echterdiek F, Schwenger V,

Živčić-Ćosić S, Katalinić N, Kuypers D, Benöhr P, Haubitz M,

Ziemann M, Nitschke M, Emmerich F,

Pisarski P, Karakizlis H, Weimer R,

Ruhenstroth A, Scherer S, Tran TH,

Mehrabi A, Zeier M and Süsal $C$ (2020) Pre-transplant HLA Antibodies

and Delayed Graft Function in the

Current Era of Kidney Transplantation.

Front. Immunol. 11:1886

doi: 10.3389/fimmu.2020.01886
Christian Morath ${ }^{1}$, Bernd Döhler ${ }^{2}$, Florian Kälble ${ }^{1}$, Luiza Pego da Silva ${ }^{1}$, Fabian Echterdiek ${ }^{3}$, Vedat Schwenger ${ }^{3}$, Stela Živčić-Ćosić ${ }^{4}$, Nataša Katalinić ${ }^{5}$, Dirk Kuypers ${ }^{6}$, Peter Benöhr ${ }^{7}$, Marion Haubitz ${ }^{7}$, Malte Ziemann ${ }^{8}$, Martin Nitschke ${ }^{9}$, Florian Emmerich ${ }^{10}$, Przemyslaw Pisarski ${ }^{11}$, Hristos Karakizlis ${ }^{12}$, Rolf Weimer ${ }^{12}$, Andrea Ruhenstroth ${ }^{2}$, Sabine Scherer ${ }^{2}$, Thuong Hien Tran ${ }^{2}$, Arianeb Mehrabi ${ }^{13}$, Martin Zeier ${ }^{1}$ and Caner Süsal ${ }^{2 *}$

${ }^{1}$ Division of Nephrology, Heidelberg University Hospital, Heidelberg, Germany, ${ }^{2}$ Institute of Immunology, Heidelberg University Hospital, Heidelberg, Germany, ${ }^{3}$ Department of Nephrology and Autoimmune Diseases, Transplantation Center, Klinikum Stuttgart, Stuttgart, Germany, ${ }^{4}$ Department of Nephrology, Dialysis and Kidney Transplantation, Department of Internal Medicine, Clinical Hospital Center Rijeka, Faculty of Medicine, University of Rijeka, Rijeka, Croatia, ${ }^{5}$ Tissue Typing Laboratory, Clinical Institute of Transfusion Medicine, Clinical Hospital Center Rijeka, Faculty of Medicine, University of Rijeka, Rijeka, Croatia, ${ }^{6}$ Department of Nephrology and Renal Transplantation, University Hospitals Leuven, Leuven, Belgium, ${ }^{7}$ Department of Nephrology and Hypertension, Center for Internal Medicine and Medical Clinic III, Klinikum Fulda, Fulda, Germany, ${ }^{8}$ Institute of Transfusion Medicine, University Hospital of Schleswig-Holstein, Lübeck, Germany, ${ }^{9}$ Medical Clinic 1, Transplantation Center, University of Lübeck, Lübeck, Germany, ${ }^{10}$ Institute for Transfusion Medicine and Gene Therapy, University Medical Center, University of Freiburg, Freiburg, Germany, ${ }^{11}$ Department of General and Digestive Surgery, University Medical Centre Freiburg, Freiburg, Germany, ${ }^{12}$ Department of Internal Medicine, University of Giessen, Giessen, Germany, ${ }^{13}$ Department of General and Transplant Surgery, University Hospital Heidelberg, Heidelberg, Germany

Delayed graft function (DGF) occurs in a significant proportion of deceased donor kidney transplant recipients and was associated with graft injury and inferior clinical outcome. The aim of the present multi-center study was to identify the immunological and non-immunological predictors of DGF and to determine its influence on outcome in the presence and absence of human leukocyte antigen (HLA) antibodies. 1,724 patients who received a deceased donor kidney transplant during 2008-2017 and on whom a pre-transplant serum sample was available were studied. Graft survival during the first 3 post-transplant years was analyzed by multivariable Cox regression. Pre-transplant predictors of DGF and influence of DGF and pre-transplant HLA antibodies on biopsy-proven rejections in the first 3 post-transplant months were determined by multivariable logistic regression. Donor age $\geq 50$ years, simultaneous pre-transplant presence of HLA class I and II antibodies, diabetes mellitus as cause of end-stage renal disease, cold ischemia time $\geq 18 \mathrm{~h}$, and time on dialysis $>5$ years were associated with increased risk of DGF, while the risk was reduced if gender of donor or recipient was female or the reason for death of donor was trauma. DGF alone doubled the risk for graft loss, more due to impaired death-censored graft than patient survival. In DGF patients, the risk of death-censored graft loss increased further if $\mathrm{HLA}$ antibodies (hazard ratio $\mathrm{HR}=4.75, P<0.001$ ) or donor-specific HLA antibodies (DSA, HR=7.39, $P<0.001$ ) were present pre-transplant. In the presence of HLA antibodies or DSA, the incidence of biopsy-proven rejections, including antibody-mediated rejections, increased significantly in patients with as well as without DGF. Recipients without DGF and without biopsy-proven rejections 
during the first 3 months had the highest fraction of patients with good kidney function at year 1, whereas patients with both DGF and rejection showed the lowest rate of good kidney function, especially when organs from $\geq 65$-year-old donors were used. In this new era of transplantation, besides non-immunological factors, also the pre-transplant presence of HLA class I and II antibodies increase the risk of DGF. Measures to prevent the strong negative impact of DGF on outcome are necessary, especially during organ allocation for presensitized patients.

Keywords: renal transplantation, HLA antibodies, donor-specific antibodies, delayed graft function, biopsy-proven rejections, antibody-mediated rejections

\section{INTRODUCTION}

Acute renal injury early after transplantation can lead to delayed graft function (DGF), increase the immunogenicity of the tissue and result in immunological rejection episodes requiring treatment (1).

The reported incidence of DGF after deceased donor kidney transplantation varies between 5 and $50 \%$ and continues to grow as kidneys from elderly donors are increasingly used due to organ shortage (2-5). DGF was reported to have a negative impact on 12-month graft function (6) and longterm graft survival, almost doubling the risk of 5-year graft loss according to a recent study (7). Interventions to reduce the incidence of DGF, such as donor dopamine infusion or machine perfusion during organ removal and transport, are still experimental and there is no approved therapy to reduce or treat DGF (8). Therefore, there is a great interest in the early detection of procurement-, donorand recipient-related risk factors of DGF to ensure optimal treatment for patients at risk. In addition to non-immunological factors, such as donor brain death, prolonged cold ischemia time and donor and recipient age, involvement of immunological factors has also been reported in the development of DGF ( 9 , 10). Earlier data from the Serum Study of the Collaborative Transplant Study (CTS) indicated that adverse events in deceased donor kidney transplantation, such as no immediate function and rejection episodes during the first 3 months post-transplant, are associated with pre-transplant presence of alloantibodies against human leukocyte antigens (HLA) (11). Patients with these early adverse events showed significantly impaired graft survival rates. In the meantime, small single-center studies indicated that donor-specific HLA antibodies (DSA) and rejection episodes are particularly detrimental in patients with DGF, while more recent large-scale studies on an involvement of DSA in DGF are lacking $(12,13)$.

Sensitive antibody detection techniques have become routine since 2008 and this might have diminished the involvement of overlooked HLA antibodies in DGF. On the other hand, the risk of DGF is expected to have increased due to the growing use of kidneys from elderly donors. The aim of the current study was to identify the immunological and non-immunological predictors of DGF and to determine the alloantibody-dependent influence of DGF on post-transplant outcomes in a large cohort of patients transplanted at 8 different transplant centers in the recent 2008-2017 period.

\section{MATERIALS AND METHODS}

\section{Study Population}

The eight participating centers provided a pre-transplant serum on patients enrolled in the prospectively designed CTS Serum Study (www.ctstransplant.org) and completed a questionnaire 3 months post-transplant which contained the following queries: immediate function within the first $24 \mathrm{~h}$ after transplantation (e.g., $>500 \mathrm{ml}$ transplant urine), dialysis during the first posttransplant week (except for single dialysis for hyperkalemia), biopsy-proven rejection during the first 3 months, including the time and type of first rejection (borderline, T-cell-mediated, antibody-mediated or mixed T-cell- and antibody-mediated). The work of the CTS is approved by the Ethics Committee of the Medical Faculty of Heidelberg University (No. 083/2005) and performed in accordance with the World Medical Association Declaration of Helsinki Ethical Principles in the currently valid version (14).

The HLA antibody screening was performed centrally in Heidelberg, using the AbScreen I and II ELISA kits of Biotest (Dreieich, Germany) which detected HLA class I and class II antibodies of the IgG isotype. Based on previous findings, an optical density (OD) of more than or equal to 300 was used as cut-off for anti-HLA positivity (15). As this kit was discontinued by the manufacturer, the LABScreen ${ }^{\mathrm{TM}}$ Mixed kit of Thermofisher/OneLambda (West Hills, CA, US) was used in $30 \%(513 / 1724)$ of the sera for detection of IgG HLA antibodies, following adjustment of the positivity cut-off to the normalized background ratio of $\geq 20$ which resembles the positivity level of AbScreen ELISA.

DGF was defined as either no graft function during the first $24 \mathrm{~h}$ and/or dialysis during the first week (except for single dialysis for hyperkalemia) after transplantation (16). Adult patients ( $\geq 18$ years) on whom we obtained a pretransplant serum and a complete 3-months questionnaire and who received a kidney-only transplant from a deceased donor between January 1, 2008 and December 31, 2017 and had a functioning graft $\geq 8$ days post-transplant were analyzed. The information obtained from the questionnaires was entered into the CTS database and connected with additional information on the transplants. In 757 cases (44\%), we obtained from the participating centers information on the presence or absence of pre-transplant DSA as determined by single antigen bead technique. 


\section{Statistical Analysis}

All cause graft, death-censored graft, and patient survival were analyzed from day 8 to the end of year 3 after transplantation. Multivariable Cox regression analysis was performed to account for the possible influence of the following confounders on graft survival: transplant year, transplant number, recipient age, recipient and donor sex and combination, diabetes mellitus as cause of end-stage renal disease, donor age, cold ischemia time, time on dialysis, HLA $\mathrm{A}+\mathrm{B}+\mathrm{DR}$ mismatches, general evaluation of the patient by the physician, latest panelreactive antibody, donor history of hypertension, trauma as cause of donor death, donation after cardiac death, other causes of marginal donor, e.g., increased serum creatinine, antibody induction therapy, pre-transplant HLA class I and II antibodies and their combination, pre-transplant DSA, and DGF. Survival rates were illustrated using the KaplanMeier method.

Significant predictors of DGF and the influence of DGF together with HLA antibodies or DSA on biopsy-proven rejections during days 8-90 post-transplant were determined by multivariable logistic regression analysis, using the same confounders as in the Cox regression analysis. A stepwise backwards elimination of non-significant confounders was applied in the multivariable regression analysis. The software package IBM SPSS Statistics 25 (SPSS Inc, Chicago, IL, US) was used.

\section{RESULTS}

\section{Predictors of DGF}

A total of 1,724 patients from 8 centers who received a deceased donor kidney transplant between 2008 and 2017 and on whom a pre-transplant serum sample and a 3 -months questionnaire on early adverse events was obtained in the framework of the

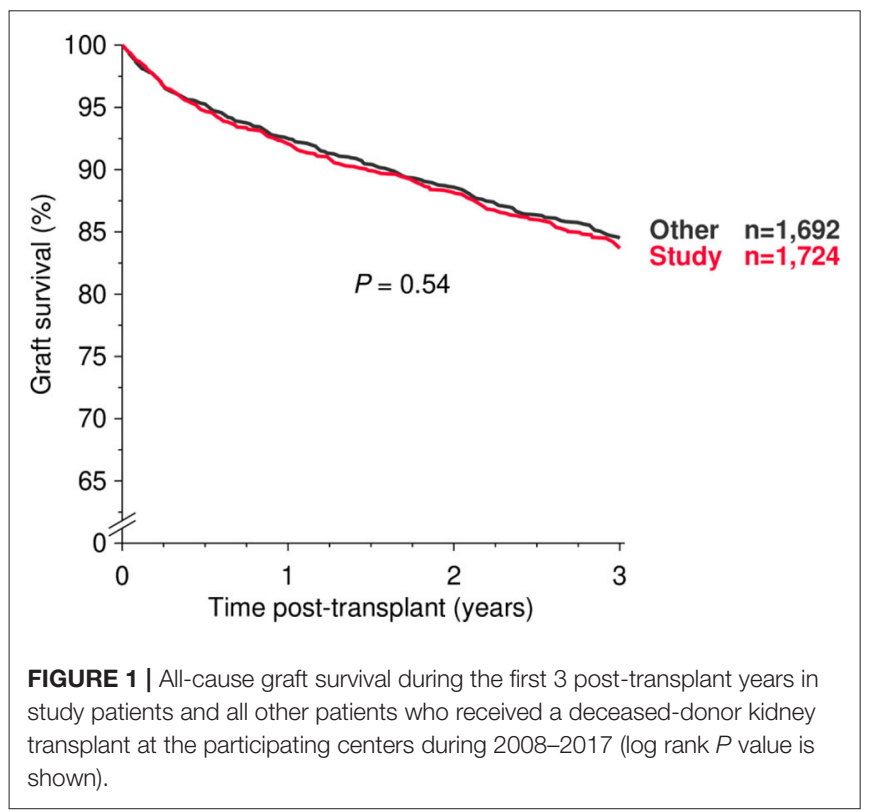

prospective Serum Study of CTS (www.ctstransplant.org) was analyzed. These patients represented a random sample and a graft survival rate which was identical with that observed in 1,692 patients who were not included in the study, but received a deceased donor kidney transplant over the same time period at the same centers (Figure 1).

Table 1 shows the demographics of the study cohort. The patients were stratified according to whether they had DGF ( $n=$ $482,28.0 \%)$ or not $(n=1,242,72.0 \%)$. DGF was more frequent in

TABLE 1 | Demographics of study patients, $n$ (\%) or mean \pm SD.

\begin{tabular}{|c|c|c|c|c|}
\hline Characteristic & $\begin{array}{l}\text { Unknown } \\
\text { (\%) }\end{array}$ & $\begin{array}{l}\text { No DGF } \\
n=1,242\end{array}$ & $\begin{array}{l}\text { With DGF } \\
n=482\end{array}$ & $P$ value \\
\hline TRANSPLANT YEAR & - & & & $<0.001$ \\
\hline 2008-2012 & & $734(59)$ & $242(50)$ & \\
\hline 2013-2017 & & $508(41)$ & $240(50)$ & \\
\hline TRANSPLANT NUMBER & - & & & 0.17 \\
\hline First transplant & & $1,059(85)$ & $398(83)$ & \\
\hline Re-transplant & & $183(15)$ & $84(17)$ & \\
\hline RECIPIENT GENDER & - & & & 0.009 \\
\hline Female & & $492(40)$ & $158(33)$ & \\
\hline Male & & $750(60)$ & $324(67)$ & \\
\hline RECIPIENT AGE (YEARS) & - & $54.2 \pm 13.0$ & $56.1 \pm 12.5$ & 0.004 \\
\hline DONOR GENDER & - & & & 0.11 \\
\hline Female & & $618(50)$ & $219(45)$ & \\
\hline Male & & $624(50)$ & $263(55)$ & \\
\hline DONOR AGE (YEARS) & - & $52.4 \pm 16.0$ & $56.9 \pm 14.3$ & $<0.001$ \\
\hline $\begin{array}{l}\text { COLD ISCHEMIA TIME } \\
\text { (HOURS) }\end{array}$ & - & $14.0 \pm 4.7$ & $14.7 \pm 5.7$ & 0.042 \\
\hline $\begin{array}{l}\text { TIME ON DIALYSIS } \\
\text { (YEARS) }\end{array}$ & - & $6.0 \pm 4.1$ & $6.8 \pm 4.6$ & $<0.001$ \\
\hline $\begin{array}{l}\text { DIABETES MELLITUS AS } \\
\text { CAUSE OF ESRD }\end{array}$ & & $85(7)$ & $51(11)$ & 0.010 \\
\hline $\begin{array}{l}\text { HLA-A+B+DR } \\
\text { MISMATCHES }\end{array}$ & - & & & 0.019 \\
\hline $0-1$ & & $243(20)$ & $78(16)$ & \\
\hline $2-4$ & & $840(68)$ & $324(67)$ & \\
\hline $5-6$ & & $159(13)$ & $80(17)$ & \\
\hline CYTOTOXIC PRA & - & & & 0.66 \\
\hline$\leq 5 \%$ & & 1,132 (91) & $436(90)$ & \\
\hline$>5 \%$ & & $110(9)$ & $46(10)$ & \\
\hline $\begin{array}{l}\text { PRE-TRANSPLANT HLA } \\
\text { ANTIBODIES* }\end{array}$ & - & & & 0.066 \\
\hline | neg, || neg & & $1,034(83)$ & $393(82)$ & \\
\hline | neg, || pos & & $61(5)$ & $21(4)$ & \\
\hline | pos, || neg & & $76(6)$ & $24(5)$ & \\
\hline | pos, || pos & & $71(6)$ & $44(9)$ & \\
\hline PRE-TRANSPLANT DSA & 56 & & & 0.27 \\
\hline No & & $481(85)$ & $157(82)$ & \\
\hline Yes & & $84(15)$ & $35(18)$ & \\
\hline
\end{tabular}

${ }^{\star}$ ELISA or LABSCreen Mixed.

DGF, delayed graft function; ESRD, end-stage renal disease; PRA, panel-reactive antibodies; DSA, donor-specific HLA antibodies. Bold means statistically significant. 
the more recent 2013-2017 than in the earlier 2008-2012 period (240/748, 32.1 vs. $242 / 976,24.8 \%, P<0.001)$. The mean of donor age was higher $(56.9$ vs. 52.4 years, $P<0.001)$ and the mean of cold ischemia time was longer ( 14.7 vs. $14.0 \mathrm{~h}, P=0.042)$ in patients with DGF than in patients without DGF. Patients who developed DGF were more likely to be male (67.2 vs. $60.4 \%, P=$ 0.009 ) and older (56.1 vs. 54.2 years, $P=0.004)$. Furthermore, they had a longer dialysis time $(6.8$ vs. 6.0 years, $P<0.001)$ and more frequently a poor HLA match (5-6 HLA-A+B+DR mismatches: $16.6 \%$ vs. $12.8 \%, P=0.019)$ and diabetes mellitus as cause of ESRD (10.6 vs. $6.8 \%, P=0.010$ ).

In the multivariable logistic regression analysis, donor age $\geq 70$ years and simultaneous presence of HLA class I and II antibodies before transplantation were the strongest predictors of DGF (odds ratio $[\mathrm{OR}]=2.32$ and $1.93, P<0.001$ and 0.002 , respectively; Table 2). They were followed by donor age 60-69 years $(\mathrm{OR}=1.64, P=0.001)$, diabetes mellitus as cause of endstage renal disease $(\mathrm{OR}=1.62, P=0.012)$, cold ischemia time $\geq 18 \mathrm{~h}(\mathrm{OR}=1.60, P<0.001)$, pre-transplant time on dialysis $>5$ years $(\mathrm{OR}=1.48, P<0.001)$ and donor age $50-59$ years $(\mathrm{OR}$ $=1.46, P=0.009)$. A reduced risk of DGF was found when the cause of donor death was trauma $(\mathrm{OR}=0.61, P=0.002)$ or when recipient or donor gender was female $(\mathrm{OR}=0.73, P=0.008$, and $\mathrm{OR}=0.74, P=0.007$, respectively).

\section{Influence of DGF and Pre-transplant HLA Antibodies on 3-Year Graft and Patient Survival}

Figure 2 shows the influence of DGF on 3-year graft survival in patients with and without pretransplant HLA antibodies (Figures 2A,B) or donor-specific HLA antibodies (DSA, Figures 2C,D).

DGF was observed more frequently in patients who received a kidney transplant from $\geq 65$ - than $<65$ year-old-donors (153/432, 35.4\% vs. 329/1,292, 25.5\%; $P<0.001)$. Only $8.5 \%$ $(13 / 153)$ of DGF patients who received a transplant from $a \geq 65$ year-old donor had HLA antibodies prior to transplantation,

TABLE 2 | Significant predictors of delayed graft function as result of multivariable logistic regression.

\begin{tabular}{lccc}
\hline Predictor & OR & $\mathbf{9 5} \% \mathbf{C I}$ & $\boldsymbol{P}$ \\
\hline Female recipient & 0.73 & $0.58-0.92$ & $\mathbf{0 . 0 0 8}$ \\
Female donor & 0.74 & $0.59-0.92$ & $\mathbf{0 . 0 0 7}$ \\
Donor 50-59 years & 1.46 & $1.10-1.95$ & $\mathbf{0 . 0 0 9}$ \\
Donor 60-69 years & 1.64 & $1.22-2.22$ & $\mathbf{0 . 0 0 1}$ \\
Donor $\geq 70$ years & 2.32 & $1.65-3.26$ & $<\mathbf{0 . 0 0 1}$ \\
Trauma as cause of donor death & 0.61 & $0.45-0.83$ & $\mathbf{0 . 0 0 2}$ \\
Cold ischemia time $\geq 18 \mathrm{~h}$ & 1.60 & $1.23-2.09$ & $<\mathbf{0 . 0 0 1}$ \\
Diabetes mellitus as cause of ESRD & 1.62 & $1.11-2.37$ & $\mathbf{0 . 0 1 2}$ \\
Time on dialysis $>5$ years & 1.48 & $1.18-1.86$ & $<\mathbf{0 . 0 0 1}$ \\
HLA class I and II AB pos & 1.93 & $1.28-2.92$ & $\mathbf{0 . 0 0 2}$
\end{tabular}

Odds ratios (OR) with 95\%-confidence intervals (Cl) are shown.

$E S R D$, end-stage renal disease; $A B$ pos, antibody-positive. Bold means statistically significant. as compared to the much higher $23.1 \%$ rate $(76 / 329, P$ $<0.001)$ in patients with transplants from a $<65$-year-old donor. Because of this ambiguous distribution of variables in the different donor age groups, we stratified the univariate results according to donor age (Figures 2A,C: $<65$-year-old donor, Figures 2B,D: $\geq 65$-year-old donor). Of note, due to a strong correlation of donor and recipient age, presumably as a result of age matching, e.g., in the Eurotransplant Senior Program, recipients of organs from $<65$-year-old donors were with a median of 52 years (interquartile range [IQR] 4359 years) significantly younger than recipients of a graft from a $\geq 65$ year-old donor (median 68 years, IQR 6570 years).

For both donor age groups $(<65$ - and $\geq 65$-year-old), overall graft survival in patients without DGF was equally good, regardless of whether or not these patients had HLA antibodies (Figures 2A,B) or even DSA (Figures 2C,D) prior to transplantation. In contrast, the 3-year graft survival was significantly reduced in patients with DGF, even in the absence of pre-transplant HLA antibodies or DSA. The worst graft survival was observed in patients who had HLA antibodies or DSA before transplantation and developed DGF.

These results were confirmed in multivariable Cox regression analyses (Table 3 ). The overall graft survival was significantly reduced in patients with DGF, more due to impaired death-censored graft than patient survival. Compared to DGF-negative patients, the risk for death-censored graft loss was 2.37-fold higher in DGF-positive patients in the absence and 4.75-fold higher in the presence of pretransplant HLA antibodies $(P<0.001$ for both). An even stronger increase of risk from 2.97- to 7.39-fold was observed in DGF-positive patients with pre-transplant DSA $(P<0.001$ for both).

\section{Influence of DGF and Pre-transplant HLA Antibodies on Biopsy-Proven Rejection Episodes During the First 3 Post-transplant Months}

Figure 3 illustrates the incidence of biopsy-proven rejection episodes from day 8 to 90 post-transplant for patients who received a kidney from a $<65$-year-old donor. Due to low patient numbers, generation of robust results for donors aged $\geq 65$ years was not possible. Irrespective of whether the patients developed DGF or not, significantly higher rates of rejections, especially antibody-mediated rejections, were seen in patients with pre-transplant HLA antibodies or DSA than in patients without such antibodies. The multivariable analysis confirmed the univariate results with higher ORs for development of rejection in patients with pretransplant HLA antibodies or DSA (Table 4). This association was statistically significant for all HLA antibody-positive groups and there was also a trend toward significance for DSA-positive patients with DGF (OR $=2.18, P=0.053)$. DGF alone had no significant effect on the occurrence of rejections from day 8 to 90 after transplantation. To avoid 


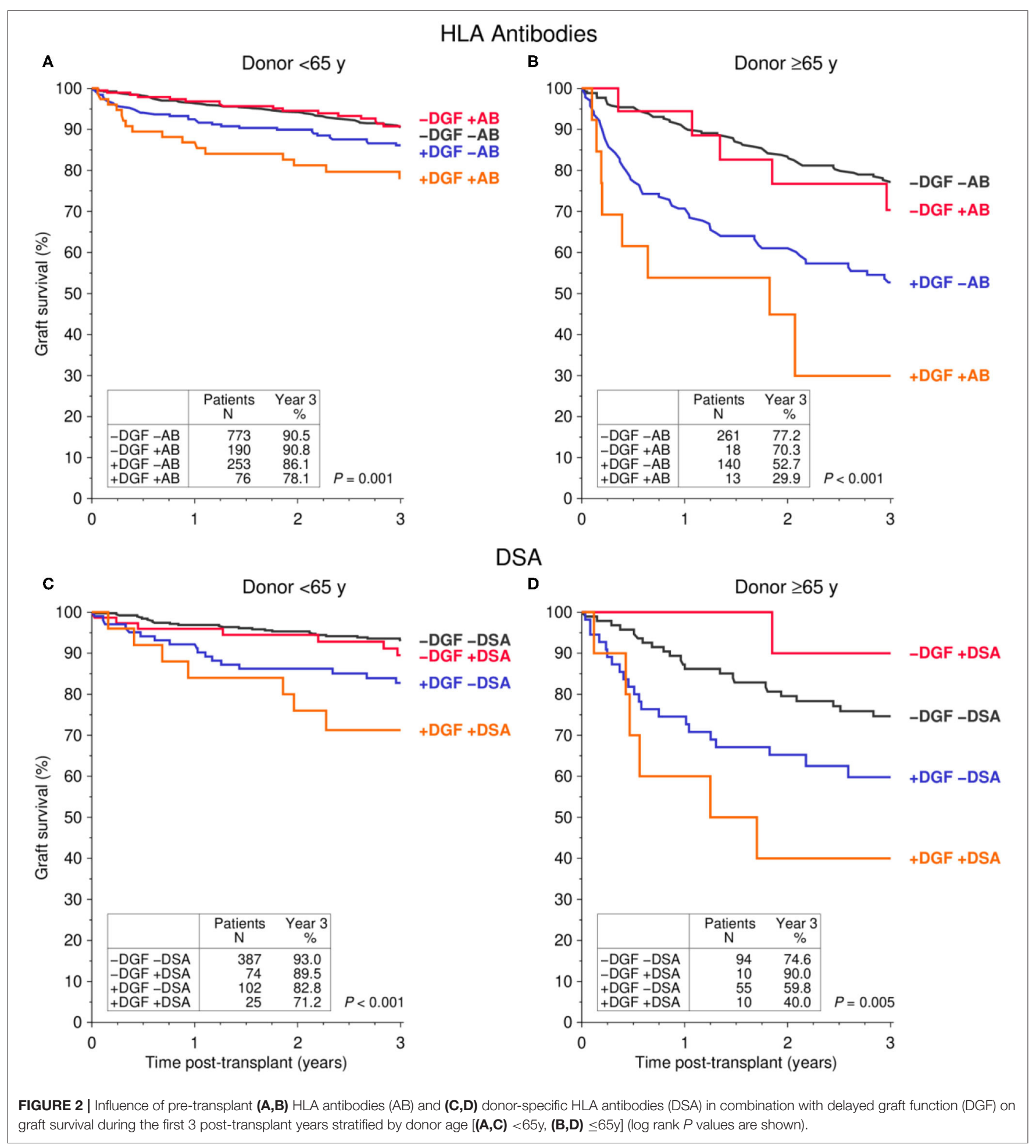

a statistical bias, rejections during the first 7 days were not considered, most probably resulting in an underestimation of the proportion of rejections in patients with DGF. Indeed, $35 \%$ and $30 \%$ of rejections in DGF-patients with or without
HLA antibodies, respectively, were observed during the first 7 days post-transplant, as compared to the much lower 25 and $18 \%$ rates in DGF-negative patients with and without HLA antibodies, respectively. 
TABLE 3 | Results of multivariable Cox regression for the influence of delayed graft function (DGF), HLA antibodies (AB), and donor-specific antibodies (DSA) on survival during first 3 post-transplant years.

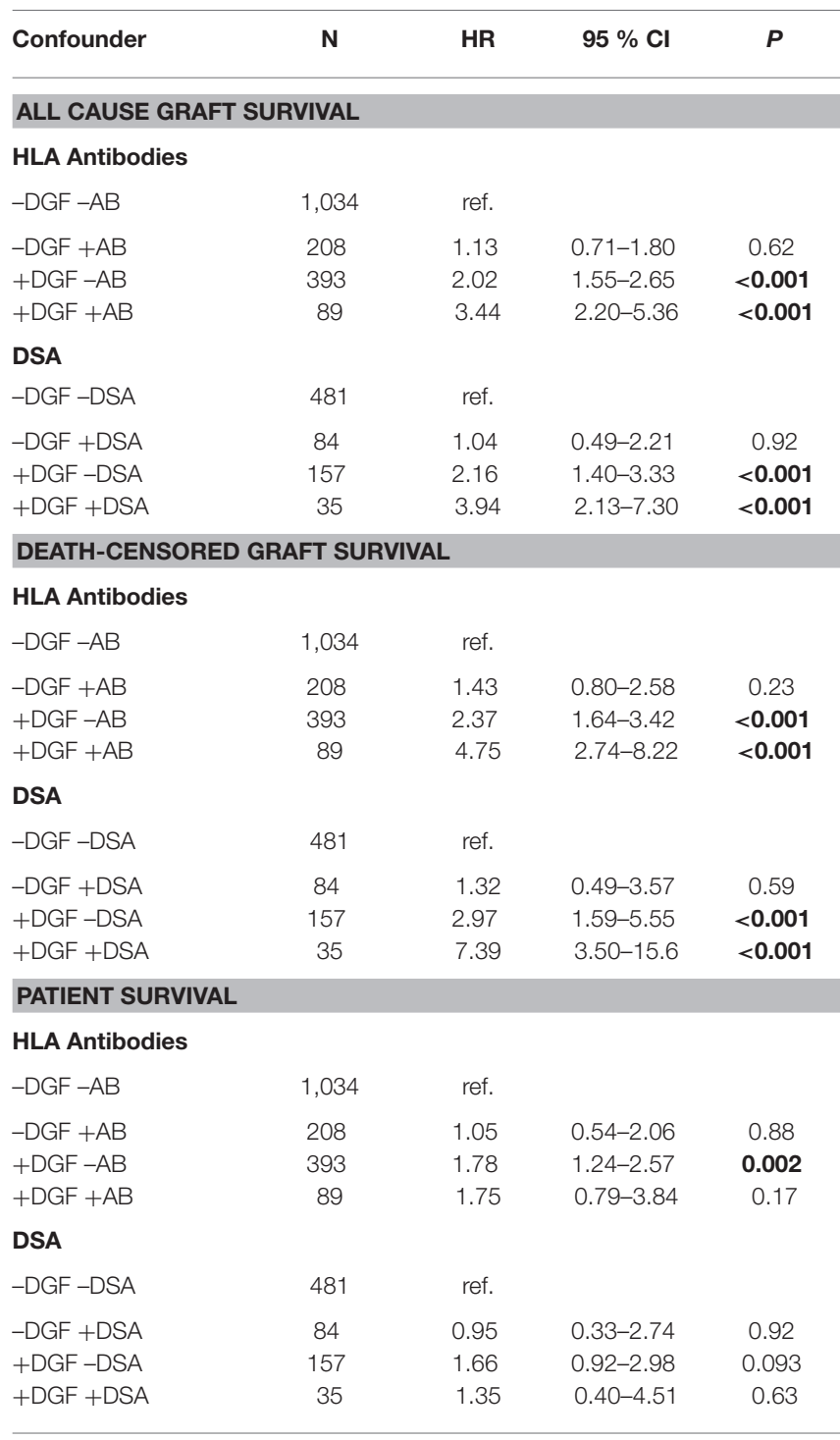

Hazard ratios (HR) with 95\%-confidence intervals (Cl) are shown. Bold means statistically significant.

\section{One-Year Kidney Graft Function Depending on DGF and Biopsy-Proven Rejection Episodes During the First 3 Post-transplant Months}

The impact of DGF and rejections on serum creatinine at year 1 post-transplant, as stratified by donor age, is shown in Figure 4. Recipients of kidney allografts from $<65$-year-old deceased donors without DGF and without rejections during days $8-90$ post-transplant had with $55.6 \%$ the highest fraction of patients with good kidney function at year 1 (creatinine $<130 \mu \mathrm{mol} / \mathrm{L}$ ) followed by patients with only DGF (37.6\%) and only rejections (37.0\%). Among patients with both DGF and rejections (REJ), the percentage of patients with good kidney function was an extremely low $27.5 \%$; accompanied by a high graft failure rate of $11.0 \%$ during the first post-transplant year (Figure 4A).

When recipients of kidneys from $\geq 65$-year-old deceased donors were analyzed, the fraction of patients with good kidney function at year 1 post-transplant was, overall, strikingly low with $20.1 \%$ in -DGF/-REJ, $10.6 \%$ in +DGF/-REJ, $6.7 \%$ in $-\mathrm{DGF} /+\mathrm{REJ}$, and $6.1 \%$ in $+\mathrm{DGF} /+\mathrm{REJ}$ cases. Conversely, the rate of graft failure during the first post-transplant year was as high as 32.7 and $29.8 \%$ in DGF patients with and without rejections, respectively (Figure $4 \mathrm{~B}$ ).

\section{DISCUSSION}

The results obtained in this large multicenter cohort of more than 1,700 deceased-donor kidney transplant recipients indicate that, in addition to well-known non-immunological factors, a broad level of sensitization prior to transplantation as reflected by the co-presence of HLA class I and class II antibodies in patient's serum increases the risk of DGF development despite the currently applied sensitive antibody testing. Patients who developed DGF demonstrated impaired graft survival in the absence, and more strongly, in the presence of pre-transplant HLA antibodies or DSA. The potentiating effect of pre-transplant alloantibodies on the impact of DGF was not evident when patient survival was analyzed. In contrast, a strong influence of DGF was observed on deathcensored graft loss when alloantibodies were present prior to transplantation, most probably due to additional immunological injury in an already damaged organ. This assumption was further supported by the high rate of diagnosed biopsy rejection episodes during days 8-90 after transplantation in pre-sensitized patients who had developed DGF up to day 7 post-transplant.

Mainly non-immunological donor-specific factors, such as age and brain death, and cold ischemia time have been associated with the development of DGF. In some previous studies, however, a significantly increased rate of DGF was found also in patients with pre-transplant HLA antibodies, whereas Quiroga et al. could not confirm such an association (17-20). Gibney et al. reported higher rates of primary non-function and DGF in 136 patients with pre-transplant DSA and we found in an independent previous series of 1,134 CTS Serum Study patients that no immediate function of the allograft was associated with the pre-transplant presence of especially HLA class I antibodies, whereas the association of this early adverse event with HLA class II antibodies reached statistical significance only in the univariate, but not in the multivariable analysis (18). The impact of double positivity for class I and class II on DGF development was not analyzed in this study. In two independent series of 4,136 and 5,315 kidney transplantations, the co-presence of class I and class II antibodies was found to be associated with strongly impaired graft survival $(15,21)$. Otten et al. reported a similar observation by analyzing the impact of pre-transplant DSA (22). The association of HLA antibodies with DGF was, however, 


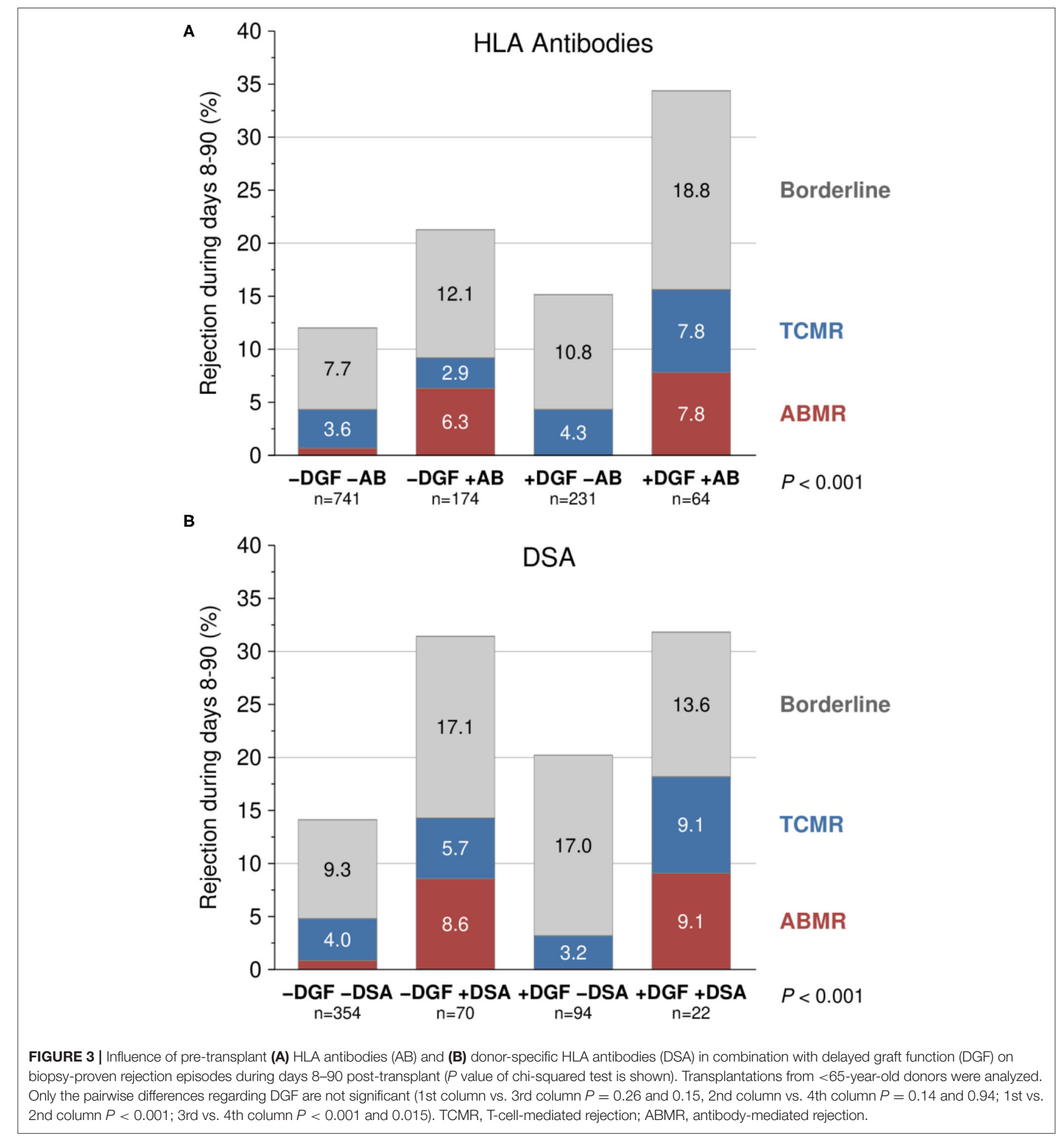

not studied in these three studies. Peräsaari et al. analyzed 771 patients from Helsinki and found that the risk of DGF was twice as high in patients with pretransplant DSA, while pretransplant non-DSA had no significant effect (12). In the same study the risk of DGF was increased also with broadness of sensitization, number of DSA and cumulative antibody strength. Similarly, broad pre-transplant sensitization, as indicated by the simultaneous presence of HLA class I and II antibodies, was a strong predictor that almost doubled the risk of DGF in our study, whereas, most probably due to the currently applied sensitive antibody testing, the presence of only HLA class I or only class II antibody showed no significant effect. It is assumable that the co-presence of both HLA antibody classes is reflective of a generally increased alloreactivity which, 
under the currently applied potent immunosuppression, can cause subclinical rejections that may go undetected in the early post-transplant phase. The rejection-mediated endothelial injury in transplant arteries could lead to a vasoconstriction, ultimately presenting the clinical picture of DGF.

In non-sensitized patients with DGF, the risk of all cause graft loss and death-censored graft loss was more than twice as high compared to the risk in patients without DGF. The risk of death-censored graft loss further increased to more than 7fold when DGF-patients had detectable DSA pretransplant, most

TABLE 4 | Results of logistic regression for the influence of HLA antibodies (AB) and donor-specific HLA antibodies (DSA) in combination with delayed graft function (DGF) on biopsy-proven rejections during days 8-90 post-transplant.

\begin{tabular}{lcccc}
\hline Predictor & $\mathbf{N}$ & OR & $\mathbf{9 5} \% \mathbf{C l}$ & $\boldsymbol{P}$ \\
\hline HLA ANTIBODIES & & & & \\
-DGF -AB & 1,034 & ref. & & \\
-DGF +AB & 208 & 1.76 & $1.20-2.59$ & $\mathbf{0 . 0 0 4}$ \\
+DGF -AB & 393 & 1.29 & $0.93-1.77$ & 0.12 \\
+DGF +AB & 89 & 2.41 & $1.45-4.01$ & $<\mathbf{0 . 0 0 1}$ \\
DSA & & & & \\
-DGF -DSA & 481 & ref. & & \\
-DGF +DSA & 84 & 2.56 & $1.51-4.36$ & $<\mathbf{0 . 0 0 1}$ \\
+DGF -DSA & 157 & 1.53 & $0.97-2.43$ & 0.068 \\
+DGF +DSA & 35 & 2.18 & $0.99-4.80$ & 0.053 \\
\hline
\end{tabular}

Odds ratios (OR) with 95\%-confidence intervals (Cl) are shown. Bold means statistically significant. likely due to an increased rate of rejection episodes. Indeed, rejection was seen significantly more often and with greater severity in antibody-positive groups than in antibody-negative groups, irrespective of whether the patients developed DGF or not, while DGF alone resulted in only a small and nonsignificant increase in rejection episodes. Interestingly, 8 and $11 \%$ of DGF patients with or without rejection, respectively, had already lost their graft 1 year after transplantation when the donor organ was $<65$ years old. For recipients of an organ from a $\geq 65$-year old donor, these figures rose to a striking 30 and $33 \%$, respectively. This is all the more remarkable because transplant failures in the first 3 months after transplantation were not included in this calculation. Taken together, our results indicate that rejection in pre-sensitized patients is particularly harmful if they receive a pre-damaged organ from an elderly donor.

Compared to patients with no DSA and no DGF, Haller et al. found an insignificant increase of graft loss in patients with either DSA or DGF, while the same risk was 3 times and significantly higher in patients with pre-transplant DSA who developed DGF. They hypothesized that inferior graft survival in DSA-positive DGF-patients may either be due to more extensive effector functions of DSA, such as complementactivation in the inflammatory environment of DGF-patients compared to patients without DGF, or overlooked rejection episodes during the DGF process causing increased harm to the allograft (13). According to our data, a complementary explanation for the observed inferior outcomes in DSA-positive patients with DGF might be the occurrence of rejections in

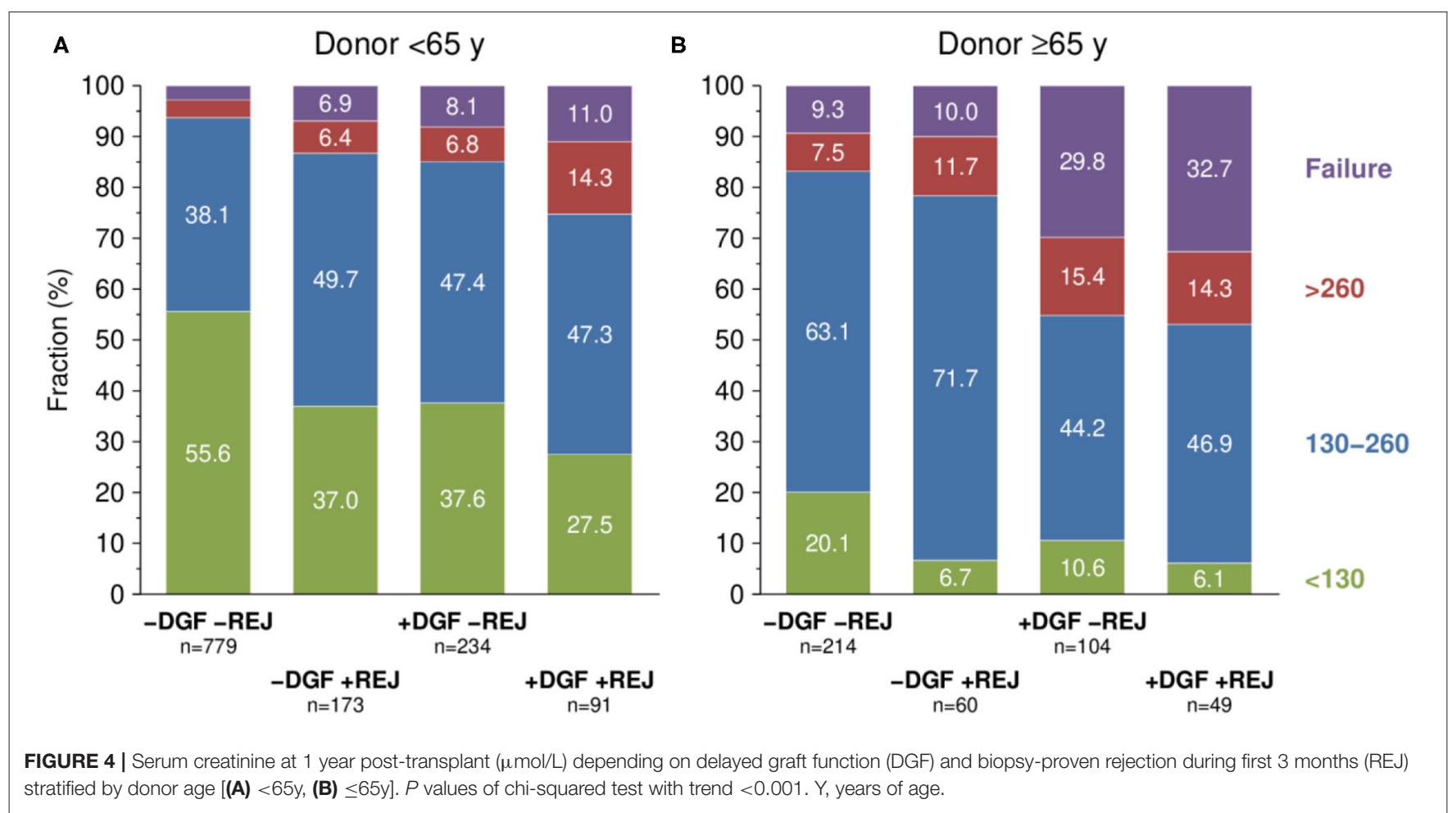




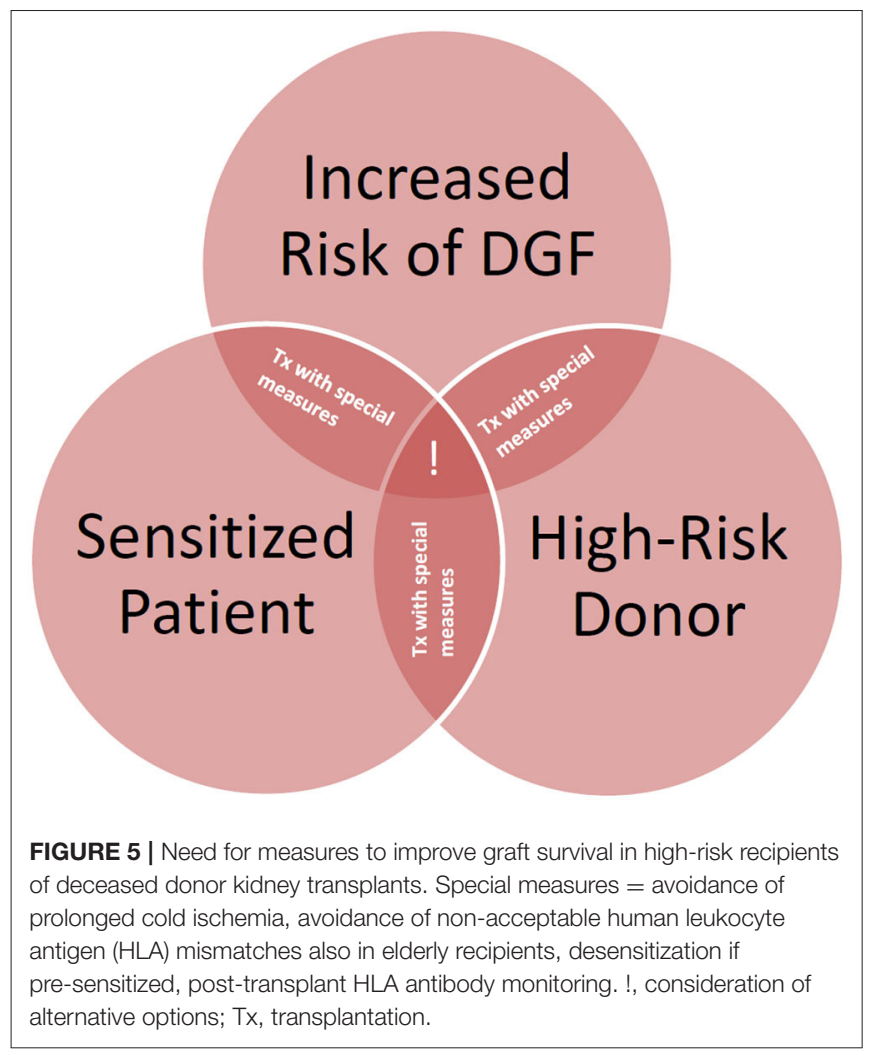

an allograft that already has been damaged by DGF. DGFassociated damage can predispose the graft to an increased risk of immune attack by upregulating major histocompatibility complex as well as non-major histocompatibility complex alloantigens in the graft. Furthermore, graft injury caused by brain death or early damage due to DGF can lead to the production of chemokines that attract immune cells into the graft and eventually result in rejections. Given the high $36 \%$ rate of DGF in patients who received an organ from a $\geq 65$-year-old donor in our study and the inferior outcomes, careful selection of recipients of these organs during organ allocation is mandatory, especially when they are presensitized.

The strength of the study is, besides the high patient number, the existence of relevant non-immunological and immunological variables, in all patients as, due to study design, only patients on whom these variables were available were analyzed. Limitations of the study are the multicenter approach, which forced us to reduce the number of variables that could be asked to the most relevant ones, and the missing information on the presence of pre-transplant DSA in 56\% of the patients. Moreover, in these patients the DSA information was delivered by the participating centers and there is heterogeneity not only in the determination but also in consideration of acceptable levels of DSA. Single antigen tests used for DSA testing stem from two different suppliers with slight differences in the sensitivity and composition of detected HLA antibody specificities and there are technical variations between the laboratories, e.g., in pretreatment of sera to eliminate the prozone effect. In addition, the centers are using different algorithms for the determination of unacceptable HLA antigen mismatches, and depending on the algorithm, more or fewer organ offers are excluded for patients with a similar antibody profile $(23,24)$. Overall, despite these limitations, this is the first large-scale study that demonstrates the alloantibody-dependent detrimental influence of DGF on post-transplant outcomes in the modern era of transplantation.

In conclusion, DGF has a strong influence on graft survival, also in the absence of pre-transplant HLA alloantibodies. However, pre-transplant HLA alloantibodies are a predisposing factor for DGF, and the presence of alloantibodies, especially that of DSA, together with DGF are associated with strongly impaired graft outcome. Adequate measures to prevent DGF in sensitized patients should be in place, especially during the allocation and transplantation of organs from elderly donors (Figure 5).

\section{DATA AVAILABILITY STATEMENT}

The raw data are available upon request to the Collaborative Transplant Study in accordance with the consents of the patients, the participating transplant centers and registries.

\section{ETHICS STATEMENT}

The studies involving human participants were reviewed and approved by Ethics committee of Heidelberg University. The patients/participants provided their written informed consent to participate in this study.

\section{AUTHOR CONTRIBUTIONS}

$\mathrm{CS}, \mathrm{BD}$, and CM designed the study, analyzed the data and wrote the paper. BD performed the statistical analysis. AR contributed to data acquisition. FK, LS, FEc, VS, SŽ-Ć, NK, DK, PB, MH, MZi, MN, FEm, PP, HK, RW, AM, and MZe delivered the sera and clinical data and contributed to the writing of the paper. CS, TT, and SS participated in testing of sera from the Heidelberg transplant center. The study received no external funding.

\section{ACKNOWLEDGMENTS}

The authors thank Tina Nonn, Kezban Ozansoy, Ramona Förtig, and the DNA and HLA teams of the Transplantation Immunology in Heidelberg for their excellent technical assistance and staff members at the Freiburg, Fulda, Giessen, Heidelberg, Leuven, Lübeck, Rijeka and Stuttgart transplant centers for supplying us with sera and clinical follow-up data. 


\section{REFERENCES}

1. Halloran PF, Hunsicker LG. Delayed graft function: state of the art, November 10-11, 2000. Summit meeting, Scottsdale, Arizona, USA. Am J Transplant. (2001) 1:115-20. doi: 10.1034/j.1600-6143.2001.10204.x

2. Ojo AO, Wolfe RA, Held PJ, Port FK, Schmouder RL. Delayed graft function: risk factors and implications for renal allograft survival. Transplantation. (1997) 63:968-74. doi: 10.1097/00007890-199704150-00011

3. Perico N, Cattaneo D, Sayegh MH, Remuzzi G. Delayed graft function in kidney transplantation. Lancet. (2004) 364:181427. doi: 10.1016/S0140-6736(04)17406-0

4. Yarlagadda SG, Coca SG, Formica RN Jr, Poggio ED, Parikh CR. Association between delayed graft function and allograft and patient survival: a systematic review and metaanalysis. Nephrol Dial Transplant. (2009) 24:103947. doi: 10.1093/ndt/gfn667

5. Siedlecki A, Irish W, Brennan DC. Delayed graft function in the kidney transplant. Am J Transplant. (2011) 11:227996. doi: 10.1111/j.1600-6143.2011.03754.x

6. Hall IE, Reese PP, Doshi MD, Weng FL, Schroppel B, Asch WS, et al. Delayed graft function phenotypes and 12-month kidney transplant outcomes. Transplantation. (2017) 101:1913-23. doi: 10.1097/TP.0000000000001409

7. Butala NM, Reese PP, Doshi MD, Parikh CR. Is delayed graft function causally associated with long-term outcomes after kidney transplantation? Instrumental variable analysis. Transplantation. (2013) 95:1008-14. doi: 10.1097/TP.0b013e3182855544

8. Schnuelle P, Druschler K, Schmitt WH, Benck U, Zeier M, Kramer BK, et al. Donor organ intervention before kidney transplantation: Head-tohead comparison of therapeutic hypothermia, machine perfusion, and donor dopamine pretreatment. What is the evidence? Am J Transplant. (2019) 19:975-83. doi: 10.1111/ajt.15317

9. Schröppel B, Legendre C. Delayed kidney graft function: from mechanism to translation. Kidney Int. (2014) 86:251-8. doi: 10.1038/ki.2014.18

10. Nashan B, Abbud-Filho M, Citterio F. Prediction, prevention, and management of delayed graft function: where are we now? Clin Transplant. (2016) 30:1198-208. doi: 10.1111/ctr.12832

11. Süsal C, Döhler B, Sadeghi M, Ovens J, Opelz G. HLA antibodies and the occurrence of early adverse events in the modern era of transplantation: a collaborative transplant study report. Transplantation. (2009) 87:136771. doi: 10.1097/TP.0b013e3181a24073

12. Perasaari JP, Kyllonen LE, Salmela KT, Merenmies JM. Pre-transplant donorspecific antihuman leukocyte antigen antibodies are associated with high risk of delayed graft function after renal transplantation. Nephrol Dial Transplant. (2016) 31:672-8. doi: 10.1093/ndt/gfv391

13. Haller J, Wehmeier C, Honger G, Hirt-Minkowski P, Gurke L, Wolff T, et al. Differential impact of delayed graft function in deceased donor renal transplant recipients with and without donor-specific HLA-antibodies. Transplantation. (2019) 103:e273-80. doi: 10.1097/TP.0000000000002802

14. Opelz G, Döhler B, Ruhenstroth A, Cinca S, Unterrainer C, Stricker L, et al. The collaborative transplant study registry. Transplant Rev. (2013) 27:43-5. doi: 10.1016/j.trre.2013.01.004
15. Süsal C, Opelz G. Kidney graft failure and presensitization against HLA class I and class II antigens. Transplantation. (2002) 73:126973. doi: 10.1097/00007890-200204270-00014

16. Mallon DH, Summers DM, Bradley JA, Pettigrew GJ. Defining delayed graft function after renal transplantation: simplest is best. Transplantation. (2013) 96:885-9. doi: 10.1097/TP.0b013e3182a19348

17. Arias M. Impact of the delayed graft function in hypersensitized kidney transplant patients. Transplant Proc. (2003) 35:16557. doi: 10.1016/S0041-1345(03)00564-5

18. Gibney EM, Cagle LR, Freed B, Warnell SE, Chan L, Wiseman AC. Detection of donorspecific antibodies using HLA-coated microspheres: another tool for kidney transplant risk stratification. Nephrol Dial Transplant. (2006) 21:2625-9. doi: 10.1093/ndt/gfl202

19. McLaren AJ, Jassem W, Gray DW, Fuggle SV, Welsh KI, Morris PJ. Delayed graft function: risk factors and the relative effects of early function and acute rejection on long-term survival in cadaveric renal transplantation. Clin Transplant. (1999) 13:266-72. doi: 10.1034/j.1399-0012.1999.130308.x

20. Quiroga I, McShane P, Koo DD, Gray D, Friend PJ, Fuggle S, et al. Major effects of delayed graft function and cold ischaemia time on renal allograft survival. Nephrol Dial Transplant. (2006) 21:1689-96. doi: 10.1093/ndt/gfl042

21. Süsal C, Döhler B, Opelz G. Presensitized kidney graft recipients with HLA class I and II antibodies are at increased risk for graft failure: a collaborative transplant study report. Hum Immunol. (2009) 70:56973. doi: 10.1016/j.humimm.2009.04.013

22. Otten HG, Verhaar MC, Borst HP, Hene RJ, van Zuilen AD. Pretransplant donor-specific HLA class-I and -II antibodies are associated with an increased risk for kidney graft failure. Am J Transplant. (2012) 12:161823. doi: 10.1111/j.1600-6143.2011.03985.x

23. Süsal C, Seidl C, Schönemann C, Heinemann FM, Kauke T, Gombos P, et al. Determination of unacceptable HLA antigen mismatches in kidney transplant recipients: recommendations of the German Society for Immunogenetics. Tissue Antigens. (2015) 86:317-23. doi: 10.1111/tan.12682

24. Süsal C, Roelen DL, Fischer G, Campos EF, Gerbase-DeLima M, Hönger $\mathrm{G}$, et al. Algorithms for the determination of unacceptable HLA antigen mismatches in kidney transplant recipients. Tissue Antigens. (2013) 82:8392. doi: $10.1111 / \tan .12137$

Conflict of Interest: The authors declare that the research was conducted in the absence of any commercial or financial relationships that could be construed as a potential conflict of interest.

Copyright (C) 2020 Morath, Döhler, Kälble, Pego da Silva, Echterdiek, Schwenger, Živčić-Ćosić, Katalinić, Kuypers, Benöhr, Haubitz, Ziemann, Nitschke, Emmerich, Pisarski, Karakizlis, Weimer, Ruhenstroth, Scherer, Tran, Mehrabi, Zeier and Süsal. This is an open-access article distributed under the terms of the Creative Commons Attribution License (CC BY). The use, distribution or reproduction in other forums is permitted, provided the original author(s) and the copyright owner(s) are credited and that the original publication in this journal is cited, in accordance with accepted academic practice. No use, distribution or reproduction is permitted which does not comply with these terms. 